\title{
Testing MACRO (version 5.1) for pesticide leaching in a Dutch clay soil
}

Rômulo P Scorza Júnior, ${ }^{1 *}$ Nicholas J Jarvis, ${ }^{2}$ Jos JTI Boesten, ${ }^{3}$ Sjoerd EATM van der Zee ${ }^{4}$ and Stéphanie Roulier ${ }^{5}$

\author{
${ }^{1}$ Embrapa Agropecuária Oeste, Caixa Postal 661, CEP 79804-970 Dourados, MS, Brazil \\ ${ }^{2}$ Department of Soil Sciences, Swedish University of Agricultural Sciences, PO Box 7014, 75007 Uppsala, Sweden \\ ${ }^{3}$ Alterra, Wageningen University and Research Centre, PO Box 47, 6700 AA Wageningen, The Netherlands \\ ${ }^{4}$ Department of Environmental Sciences, Wageningen University and Research Centre, Nieuwe Kanaal 11, 6709PA Wageningen, The \\ Netherlands \\ ${ }^{5}$ Institute of Terrestrial Ecology, ETH Zurich, CH-8092 Zurich, Switzerland
}

\begin{abstract}
Testing of pesticide leaching models against comprehensive field-scale measurements is necessary to increase confidence in their predictive ability when used as regulatory tools. Version 5.1 of the MACRO model was tested against measurements of water flow and the behaviour of bromide, bentazone [3-isopropyl-1H-2,1,3benzothiadiazin-4(3H)-one-2,2-dioxide] and imidacloprid [1-(6-chloro-3-pyridylmethyl)- $\mathrm{N}$-nitroimidazolidin-2ylideneamine] in a cracked clay soil. In keeping with EU (FOCUS) procedures, the model was first calibrated against the measured moisture profiles and bromide concentrations in soil and in drain water. Uncalibrated pesticide simulations based on laboratory measurements of sorption and degradation were then compared with field data on the leaching of bentazone and imidacloprid. Calibrated parameter values indicated that a high degree of physical non-equilibrium (i.e. strong macropore flow) was necessary to describe solute transport in this soil. Comparison of measured and simulated bentazone concentration profiles revealed that the bulk of the bentazone movement in this soil was underestimated by MACRO. Nevertheless, the model simulated the dynamics of the bentazone breakthrough in drain water rather well and, in particular, accurately simulated the timing and the concentration level of the early bentazone breakthrough in drain water. The imidacloprid concentration profiles and its persistence in soil were simulated well. Moreover, the timing of the early imidacloprid breakthrough in the drain water was simulated well, although the simulated concentrations were about 2-3 times larger than measured. Deep groundwater concentrations for all substances were underestimated by MACRO, although it simulated concentrations in the shallow groundwater reasonably well. It is concluded that, in the context of ecotoxicological risk assessments for surface water, MACRO can give reasonably good simulations of pesticide concentrations in water draining from cracking clay soils, but that prior calibration against hydrologic and tracer data is desirable to reduce uncertainty and improve accuracy.
\end{abstract}

(C) 2007 Society of Chemical Industry

Keywords: preferential flow; pesticide leaching; MACRO; groundwater contamination

\section{INTRODUCTION}

Preferential transport through macropores (e.g. shrinkage cracks, earthworm and root channels) in the unsaturated zone can increase the risk of groundwater and surface water contamination by pesticides, because the biologically and chemically reactive topsoil is quickly bypassed. As a result, pesticides can rapidly reach subsoil layers where transformation and sorption processes are generally less effective. Preferential transport of pesticides in macropores has gained much attention from soil scientists in recent decades, and many field studies have demonstrated its occurrence. ${ }^{1-4}$ However, the information gained from such field studies is often limited owing to the difficulty in experimentally quantifying macropore flow effects, the restricted duration of the experiments and also the limited number of pesticides studied compared with the large number in use today. ${ }^{5}$ Pesticide leaching models can play an important role in overcoming these limitations.

Many solute leaching models that account for preferential flow processes have been developed during the past 15 years using different approaches. ${ }^{6-11}$ One promising approach is that used in dual-permeability models, which consists in partitioning the soil into two pore domains, each being characterized by a porosity, a water pressure and a solute concentration. ${ }^{11}$ One such model, MACRO, ${ }^{11}$ is now being used to support authorities in decisions concerning the approval of pesticide registration in the European Union. ${ }^{12,13}$ MACRO was selected as it calculates macropore flow with a physics-based approach that is also relatively simple and parsimonious with respect to data requirements. In comparison with the widely used advection-dispersion equation, which does not account for macropore flow, MACRO

* Correspondence to: Rômulo P Scorza Júnior, Embrapa Agropecuária Oeste, Caixa Postal 661, CEP 79804-970 Dourados, MS, Brazil E-mail: romulo@cpao.embrapa.br

(Received 28 November 2006; revised version received 26 March 2007; accepted 5 April 2007)

Published online 20 August 2007; DOI: 10.1002/ps.1434 
requires only four additional parameters. In EU procedures, MACRO is used to predict pesticide leaching to drains for a number of 'representative worst-case' scenarios, some of which are precalibrated with respect to water flow and tracer transport. ${ }^{14}$ However, in common with other pesticide leaching models, ${ }^{15}$ only a limited number of comprehensive field-scale tests of MACRO have been carried out, and more are needed to improve confidence in the ability of the model to predict pesticide leaching with sufficient accuracy for this purpose. In one such test on a structured clay soil at Lanna, Sweden, Larsson and Jarvis ${ }^{1}$ showed that calibrated MACRO simulations of bromide and bentazone contents in the soil profile were within one standard deviation of the measured values. Good predictions of the initial breakthrough of bromide and bentazone in drain flow were also obtained by the model. However, the short-term fluctuations of bromide and bentazone concentrations in drain flow were not well captured by the model. Larsson and Jarvis ${ }^{1}$ suggested that uncertainty in the boundary conditions (e.g. precipitation and groundwater inflow/outflow) and the simplified description of first-order mass exchange between micropores and macropores were the main sources of deviations between measurements and simulations. Using the Lanna dataset, Larsbo and Jarvis ${ }^{16}$ demonstrated that significant parameter and predictive uncertainty remained even after careful calibration of the model against this detailed data. It was concluded that only the most comprehensive datasets can support sufficiently unambiguous tests of detailed simulation models such as MACRO.

The availability of the Andelst dataset ${ }^{3}$ provides such an opportunity for testing the performance of the MACRO model. This comprehensive dataset includes detailed high-time-resolution measurements of site hydrology and the leaching behaviour of a tracer and two contrasting pesticides, one weakly and one strongly sorbing, in a tile-drained cracking clay soil. Recently, a new version of MACRO (5.1) has been released, with more accurate and faster numerical solution methods, that allows the use of automated calibration procedures. Thus, the main objective of this study was to evaluate the ability of MACRO (v.5.1) to simulate the behaviour of water, bromide and two pesticides with contrasting mobility as measured in the Andelst field-scale experiment.

\section{MODEL DESCRIPTION}

MACRO 5.1 is a physically based, one-dimensional, numerical model that simulates transient water flow and solute transport at the plot scale. The MACRO 5.1 model will be described here briefly, focusing on features that are most relevant for this study. A full description of MACRO is given elsewhere. ${ }^{11}$

The total porosity in each soil layer is partitioned into micropores and macropores. Each of these flow domains is characterized by a degree of saturation, conductivity and flux. The Richards equation is used to calculate the vertical movement of water in the micropores:

$$
C \frac{\partial h_{\mathrm{mi}}}{\partial t}=-\frac{\partial}{\partial z}\left[K_{\mathrm{mi}}\left(\frac{\partial h_{\mathrm{mi}}}{\partial z}+1\right)\right]-\sum S_{i}
$$

where $C$ is the water capacity $\left(d \theta / d h_{\mathrm{mi}}\right)\left(\mathrm{cm}^{-1}\right), h_{\mathrm{mi}}$ is the soil water pressure head in the micropores $(\mathrm{cm}), t$ is time (days), $z$ is depth $(\mathrm{cm}), K_{\mathrm{mi}}$ is the hydraulic conductivity in the micropores $\left(\mathrm{cm} \mathrm{day}{ }^{-1}\right)$ and $S_{i}$ are sink/source terms to account for water exchange with macropores, drainage and root water uptake $\left(\mathrm{day}^{-1}\right)$. Soil water retention in the micropores is described by a modified form of the van Genuchten equation, ${ }^{17}$ while hydraulic conductivity is calculated with the Mualem model. ${ }^{18}$ A simplified approach is used to describe the water flow in the macropores, assuming a non-capillary, gravity-driven process (i.e. $\partial h / \partial z=0)$. Therefore, description of the soil water pressure in the macropores is not required. The hydraulic conductivity function in the macropores, $K_{\text {ma }}\left(\mathrm{cm}\right.$ day $\left.^{-1}\right)$, is given as a simple power law function:

$$
K_{\mathrm{ma}}=\left(K_{\mathrm{s}}-K_{\mathrm{b}}\right) S_{\mathrm{ma}}^{n^{*}}
$$

and

$$
S_{\mathrm{ma}}=\frac{\theta_{\mathrm{ma}}}{\theta_{\mathrm{s}}-\theta_{\mathrm{b}}}
$$

where $K_{\mathrm{s}}$ is the saturated hydraulic conductivity (cm day $\left.^{-1}\right), K_{\mathrm{b}}$ is the saturated hydraulic conductivity of micropores $\left(\mathrm{cm} \mathrm{day}{ }^{-1}\right), S_{\mathrm{ma}}$ is the effective saturation in the macropores $\left(\mathrm{cm}^{3} \mathrm{~cm}^{-3}\right), n^{*}$ is a kinematic exponent related to the macropore size distribution, $\theta_{\mathrm{ma}}$ is the volume fraction of liquid phase in the macropores $\left(\mathrm{cm}^{3} \mathrm{~cm}^{-3}\right), \theta_{\mathrm{s}}$ is the saturated volume fraction of liquid phase $\left(\mathrm{cm}^{3} \mathrm{~cm}^{-3}\right)$ and $\theta_{\mathrm{b}}$ is the volume fraction of liquid phase at the micropore/macropore boundary $\left(\mathrm{cm}^{3} \mathrm{~cm}^{-3}\right)$. Water exchange rates between micropores and macropores [used as $S_{\mathrm{w}}$ in Eqn (1)] are calculated as a function of an effective aggregate half-width, $d(\mathrm{~cm})$, using an approximate physically based first-order function, which neglects the influence of gravity and assumes a rectangular slab geometry for the aggregates: ${ }^{19,20}$

$$
S_{\mathrm{w}}=\left(\frac{G_{\mathrm{f}} D_{\mathrm{w}} \gamma_{\mathrm{w}}}{d^{2}}\right)\left(\theta_{\mathrm{b}}-\theta_{\mathrm{mi}}\right)
$$

where $G_{\mathrm{f}}$ is a dimensionless geometry factor (set at a value of 3 for a rectangular slab geometry ${ }^{21}$ ), $D_{\mathrm{w}}$ is an effective water diffusivity $\left(\mathrm{cm}^{2} \mathrm{day}^{-1}\right)$ and $\gamma_{\mathrm{w}}$ is a dimensionless scaling factor to match the approximate and exact solutions to the diffusion problem. ${ }^{22}$ In MACRO, $\gamma_{w}$ is set at an average value of $0.8 .^{23}$

MACRO needs daily or hourly rainfall and meteorological data (daily maximum and minimum air temperatures, daily wind speed, daily vapour pressure and daily global radiation), used in the calculation of potential evapotranspiration by the 
Penman-Monteith method. ${ }^{24}$ Actual transpiration [i.e. the rate of soil water extraction by plant roots, $S_{\mathrm{u}}$ in Eqn (1)], is calculated using a simple empirical function as described by Jarvis. ${ }^{25}$ The uptake of water by the roots can occur in both regions in the model, although it is assumed to be preferentially extracted from the macropores.

The top boundary condition for water flow in dual-permeability models is very critical because it determines the partitioning of net precipitation and/or irrigation between micropores and macropores. ${ }^{26,27}$ Basically, three different situations of flow can occur at the soil surface in MACRO. In the first situation, the precipitation rate is smaller than the infiltration capacity of the micropores. Then all rainfall will infiltrate into the micropores. In the second situation, precipitation is greater than the infiltration capacity of the soil matrix but smaller than the infiltration capacity of the macropores. Then both micropores and macropores receive water. Finally, a third situation can occur in which the precipitation rate exceeds the total infiltration capacity of the soil. Then the excess of water at the soil surface leads to overland flow.

The drainage rate for saturated micropore and macropore domains in each layer of the soil profile, $q_{\mathrm{d}}\left(\mathrm{cm}\right.$ day $\left.^{-1}\right)$, is calculated using seepage potential theory for layers above drain depth ${ }^{28}$ and the Hooghoudt equation for layers below. ${ }^{11}$ Total drain flow is given by the sum of drain flow from micropore and macropore domains. Percolation to groundwater, $q_{\text {out }}\left(\mathrm{cm} \mathrm{day}^{-1}\right)$, is calculated as a linear function of the water table height, $H(\mathrm{~cm})$ :

$$
q_{\mathrm{out}}=q_{\mathrm{const}}\left(\frac{K}{K_{\mathrm{s}}}\right) H
$$

where $q_{\text {const }}\left(\right.$ day $\left.^{-1}\right)$ is an empirical parameter that controls percolation to groundwater, $K$ is the saturated hydraulic conductivity of either the macropore or micropore domain in the deepest horizon of the profile and $K_{\mathrm{S}}\left(\mathrm{cm} \mathrm{day}{ }^{-1}\right)$ is the overall saturated hydraulic conductivity in the deepest horizon of the profile.

Soil temperatures are calculated from the heat conductivity equation using air temperatures to define the boundary conditions. Soil thermal properties are defined as a function of soil physical properties. ${ }^{23}$

Solute transport in the micropores is calculated using the convection-dispersion equation:

$$
\begin{aligned}
& \frac{\partial\left(\theta_{\mathrm{mi}} C_{\mathrm{L}, \mathrm{mi}}+(1-f) X \rho\right)}{\partial t} \\
& \quad=\frac{\partial}{\partial z}\left(D \theta_{\mathrm{mi}} \frac{\partial C_{\mathrm{L}, \mathrm{mi}}}{\partial z}-q C_{\mathrm{L}, \mathrm{mi}}\right)-\sum R_{i}
\end{aligned}
$$

where $C_{\mathrm{L}, \mathrm{mi}}$ is the concentration of solute in the liquid phase in the micropores $\left(\mathrm{g} \mathrm{cm}^{-3}\right), f$ is the fraction of sorption sites attributed to the macropores, $X$ is the content of solute sorbed onto the solid phase $\left(\mathrm{g} \mathrm{g}^{-1}\right), \rho$ is the dry soil bulk density $\left(\mathrm{g} \mathrm{cm}^{-3}\right), D$ is the dispersion coefficient $\left(\mathrm{cm}^{2} \mathrm{day}^{-1}\right), q$ is the volume flux of water in soil $\left(\mathrm{cm} \mathrm{day}^{-1}\right)$ and $\Sigma R_{i}$ represents the source/sink terms regarding mass exchange between flow domains, solute uptake by crop, solute transformation and losses to drains. Coefficient $D$ is calculated from

$$
D=L_{\mathrm{dis}} v_{\mathrm{mi}}+D_{0} \zeta_{\mathrm{L}}
$$

where $L_{\mathrm{dis}}$ is the dispersion length $(\mathrm{cm}), v_{\mathrm{mi}}$ is the pore water velocity in the micropores $\left(\mathrm{cm} \mathrm{day}{ }^{-1}\right.$ ) given by $q / \theta_{\mathrm{mi}}, D_{0}$ is the coefficient of solute diffusion in the water $\left(\mathrm{cm}^{2} \mathrm{day}^{-1}\right)$ and $\zeta_{\mathrm{L}}$ is the tortuosity factor for diffusion in the liquid phase. ${ }^{29}$ In macropores, solute dispersion is neglected because solute transport is assumed to be dominated by convection. The partitioning of reactive solutes between liquid and solid phases in either flow domain is described using the Freundlich isotherm:

$$
X=K_{\mathrm{F}} C_{\mathrm{REF}}\left(\frac{C_{\mathrm{L}, \mathrm{mi} / \mathrm{ma}}}{C_{\mathrm{REF}}}\right)^{N}
$$

where $K_{\mathrm{F}}$ is the Freundlich sorption coefficient $\left(\mathrm{cm}^{3} \mathrm{~g}^{-1}\right), C_{\mathrm{L}, \mathrm{mi} / \mathrm{ma}}$ is the concentration of solute in the liquid phase in either micropores or macropores $\left(\mathrm{g} \mathrm{cm}^{-3}\right), N$ is the Freundlich exponent and $C_{\mathrm{REF}}$ is a reference concentration $\left(\mathrm{g} \mathrm{cm}^{-3}\right)$ introduced to make the units of $K_{\mathrm{F}}$ independent of $N .{ }^{30} \mathrm{MACRO}$ can also deal with kinetic sorption, but instantaneous equilibrium between sorbed and solution phases was assumed in the present study.

The rate of solute exchange between micropores and macropores, $R_{\mathrm{e}}\left(\mathrm{g} \mathrm{cm}^{-3} \mathrm{day}^{-1}\right)$, is given by a combination of diffusion and convection: ${ }^{19,31}$

$$
R_{\mathrm{e}}=\left(\frac{G_{\mathrm{f}} D_{\mathrm{e}} \theta_{\mathrm{mi}}}{d^{2}}\right)\left(C_{\mathrm{L}, \mathrm{ma}}-C_{\mathrm{L}, \mathrm{mi}}\right)+S_{\mathrm{w}} C_{\mathrm{L}, \mathrm{mi} / \mathrm{ma}}
$$

where $D_{\mathrm{e}}$ is an effective diffusion coefficient $\left(\mathrm{cm}^{2}\right.$ day $\left.^{-1}\right), C_{\mathrm{L}, \mathrm{ma}}$ and $C_{\mathrm{L}, \mathrm{mi}}$ are mass concentrations of solute in the liquid phase $\left(\mathrm{g} \mathrm{cm}^{-3}\right)$ in macropores and micropores respectively and $C_{\mathrm{L}, \mathrm{mi} / \mathrm{ma}}$ indicates either $C_{\mathrm{L}, \mathrm{ma}}$ or $C_{\mathrm{L}, \mathrm{mi}}$ depending on the direction of the water flow. Coefficient $D_{\mathrm{e}}$ is approximated by

$$
D_{\mathrm{e}}=D_{0} \zeta_{\mathrm{L}} S_{\mathrm{ma}}
$$

The rate of solute discharge by the drainage system, $R_{\mathrm{d}}\left(\mathrm{g} \mathrm{cm}^{-3} \mathrm{day}^{-1}\right)$, is calculated assuming complete mixing of solute in the lateral direction in each soil layer:

$$
R_{\mathrm{d}}=\frac{q_{\mathrm{d}}}{\Delta z} C_{\mathrm{L}, \mathrm{mi} / \mathrm{ma}}
$$

The rate of solute uptake by plant roots, $R_{\mathrm{U}}$ (g $\mathrm{cm}^{-3}$ day $^{-1}$ ), is described as a passive process:

$$
R_{\mathrm{U}}=f_{\mathrm{u}} S C_{\mathrm{L}, \mathrm{mi} / \mathrm{ma}}
$$

where $f_{\mathrm{u}}$ is the transpiration stream concentration factor ${ }^{32}$ and $S$ is the root water uptake $\left(\right.$ day $\left.^{-1}\right)$.

Solute transformation in each soil phase and flow domain is described with first-order kinetics. The 
actual transformation rate in the field, $k\left(\right.$ day $\left.^{-1}\right)$, is predicted from a laboratory-measured reference value, $k_{\mathrm{REF}}\left(\mathrm{day}^{-1}\right)$, using reduction factors to account for the influence of environmental conditions: ${ }^{32}$

$$
k=k_{\mathrm{REF}} f_{T} f_{\theta}
$$

where $f_{\mathrm{T}}$ and $f_{\theta}$ are the reduction factors to account for the influence of temperature and soil moisture content respectively. Factor $f_{\mathrm{T}}$ is given by a numerical approximation of the Arrhenius equation ${ }^{30}$ modified for low temperatures:

$$
\begin{gathered}
f_{T}=\mathrm{e}^{\alpha\left(T-T_{\mathrm{REF}}\right)} \text { for } T>5^{\circ} \mathrm{C} \\
f_{T}=\left(\frac{T}{5}\right) \mathrm{e}^{\alpha\left(5-T_{\mathrm{REF}}\right)} \text { for } 0 \leq T \leq 5^{\circ} \mathrm{C} \\
f_{T}=0 \text { for } T<0{ }^{\circ} \mathrm{C}
\end{gathered}
$$

where $T$ is soil temperature $\left({ }^{\circ} \mathrm{C}\right), T_{\mathrm{REF}}$ is $T$ at reference conditions and $\alpha$ is a composite parameter $\left({ }^{\circ} \mathrm{C}^{-1}\right)$ dependent on $T, T_{\mathrm{REF}}$, molar activation energy and the gas constant. The reduction factor $f_{\theta}$ is calculated from

$$
\begin{gathered}
f_{\theta}=1, \quad \theta>\theta_{100} \\
f_{\theta}=\left[\left(\theta-\frac{\theta_{\mathrm{w}}}{2} / \theta_{100}-\frac{\theta_{\mathrm{w}}}{2}\right)\right]^{B}, \quad \frac{\theta_{\mathrm{w}}}{2}<\theta<\theta_{100} \\
f_{\theta}=0, \quad \theta<\frac{\theta_{\mathrm{w}}}{2}
\end{gathered}
$$

where $\theta$ is the volume fraction of liquid phase $\left(\mathrm{cm}^{3} \mathrm{~cm}^{-3}\right), \theta_{100}$ is the volume fraction of liquid phase $\left(\mathrm{cm}^{3} \mathrm{~cm}^{-3}\right)$ at a pressure head of $100 \mathrm{~cm}, \theta_{\mathrm{W}}$ is the volume fraction of liquid phase at the wilting point $\left(\mathrm{cm}^{3} \mathrm{~cm}^{-3}\right)$ and $B$ is a constant.

The water routed into the macropores is characterized by a concentration $C_{\mathrm{ma}}\left(\mathrm{g} \mathrm{cm}^{-3}\right)$, which is calculated assuming complete mixing with solute stored in the soil liquid phase of a shallow mixing depth $z_{\mathrm{d}}(\mathrm{cm})$ at the soil surface: ${ }^{33}$

$$
C_{\mathrm{ma}}=\frac{Q_{\mathrm{s}}+\left(P C_{\mathrm{P}}\right)}{P+\left(z_{\mathrm{d}}\left(\theta_{\mathrm{mi}, \mathrm{sur}}+(1-f) \rho_{\mathrm{sur}} K_{\mathrm{f}}\right)\right)}
$$

where $Q_{\mathrm{s}}$ is the amount of solute stored in $z_{\mathrm{d}}\left(\mathrm{g} \mathrm{cm}^{-2}\right)$, $C_{\mathrm{P}}$ is the solute concentration in the precipitation ( $\mathrm{g}$ $\left.\mathrm{cm}^{-3}\right), \theta_{\mathrm{mi} \text { sur }}$ is the volumetric fraction of liquid phase in the mixing depth $z_{\mathrm{d}}\left(\mathrm{cm}^{3} \mathrm{~cm}^{-3}\right)$ and $\rho_{\text {sur }}$ is the dry soil bulk density in the mixing depth $z_{\mathrm{d}}\left(\mathrm{g} \mathrm{cm}^{-3}\right)$.

\section{MODEL PARAMETERIZATION, TESTING AND CALIBRATION}

\subsection{Field experiment}

The field experiment has been described in detail elsewhere ${ }^{3}$ and will be described here only very briefly. The experiment was carried out from April 1998 until April 1999 in the municipality of Andelst $\left(51^{\circ} 53^{\prime} \mathrm{N}\right.$, $5^{\circ} 43^{\prime} \mathrm{E}, 8 \mathrm{~m}$ above sea level) in the Netherlands.
Cumulative rainfall during the entire experimental period was about $1150 \mathrm{~mm}$. This amount in about 1 year is exceptionally high for Dutch conditions, as the annual average of total rainfall between 1971 and 2000 in the Netherlands was about $800 \mathrm{~mm} .{ }^{34}$ The soil is a young Holocene river bank deposit of the river Rhine, classified as Eutric Fluvisol. ${ }^{35}$ Its clay layer was about $3 \mathrm{~m}$ deep and underlaid with a thick layer of coarse sand. The clay content of the top $120 \mathrm{~cm}$ ranged from 28 to $37 \%$. After dry periods, shrinkage cracks were observed at the soil surface of the entire experimental field. Permanent macropores as a result of root decay and earthworm activity were regularly found in the $30-100 \mathrm{~cm}$ soil layer during the sampling of soil profile. The surface area of the field was $1.2 \mathrm{ha}$. Tile drains were located at $0.8 \mathrm{~m}$ depth and at $10 \mathrm{~m}$ spacing. Winter wheat was sown in the autumn of 1997. Bromide and bentazone were applied on 7 April 1998 and imidacloprid was applied on 27 May 1998. Rainfall, groundwater level and drain discharges in two pipes were continuously measured at the experimental field. The total experimental area comprised the whole catchment area of six drains. Each drain pipe was the result of coupling the outlets of three tile drains with an intermediate distance of $10 \mathrm{~m}$. The catchment area of the two pipes was 0.63 and 0.57 ha respectively. Groundwater and drain water were sampled and analysed for bromide, bentazone and imidacloprid. On six occasions (i.e. at 22, 69, 125, 167, 239 and 378 days after bromide and bentazone application), soil profiles were sampled up to $120 \mathrm{~cm}$ depth at 16 plots in the field (one sample per plot). This was done using a steel corer that was built to collect soil cores in PVC tubes (used as liners inside the corer). This corer was pressed vertically into the soil with a hydraulic wheeled excavator. The 16 soil columns of each sampling time were not analysed individually, but the corresponding layers of four plots were mixed to reduce analytical efforts. Similarly, groundwater samples from the same filter depths of four plots were mixed for pesticide analysis. Using these samples, moisture profiles and concentration profiles of bromide, bentazone and imidacloprid were measured. In the laboratory, soil water retention curves and unsaturated hydraulic conductivity were measured simultaneously using Wind's evaporation method, ${ }^{36}$ and saturated hydraulic conductivity was measured using the constant head method. ${ }^{37}$ The degradation rate and sorption of bentazone and imidacloprid were also measured in the laboratory in incubation and batch experiments.

\subsection{Model parameterization}

To provide adequate numerical accuracy, the $2.8 \mathrm{~m}$ soil profile was divided into 60 numerical compartments with thicknesses varying between $0.003 \mathrm{~m}$ (topsoil) and $0.05 \mathrm{~m}$ (subsoil). Seven different soil horizons $(0-10,10-20,20-35,35-55,55-75,75-120$ and $120-280 \mathrm{~cm}$ ) were identified. Initial soil temperatures 
were calculated by linearly interpolating the measurements at $0.05,0.5$ and $1 \mathrm{~m}$ depth. Initial soil water contents were based on measurements down to $0.9 \mathrm{~m}$. For the deeper layers, saturated water contents were assumed because the phreatic groundwater level was initially at $0.9 \mathrm{~m}$. Hourly rainfall rates measured at the experimental site $^{3}$ were used as input for the model. The driving variables required for the calculation of Penman-Monteith evapotranspiration (i.e. daily maximum and minimum air temperatures, wind speed, vapour pressure and global radiation) were obtained from the meteorological station 'de Haarweg' (part of the Wageningen University and Research Centre), which is located $10 \mathrm{~km}$ from the experimental field.

Van Genuchten parameters to describe hydraulic functions in the micropores (Table 1) were derived from site-specific laboratory experiments ${ }^{38}$ using the RETC package. ${ }^{39}$ The saturated hydraulic conductivities $\left(K_{\mathrm{s}}\right)$ were estimated on the basis of measured values obtained using the constant head method, ${ }^{37}$ supported by near-saturated hydraulic conductivities obtained using Wind's evaporation method. ${ }^{36}$ Saturated water contents $\left(\theta_{\mathrm{s}}\right)$ were considered to be equal to $96 \%$ of the total porosity $(\varphi)$ to account for entrapped air, and $\varphi$ was derived from the dry bulk density using a density of the soil solid phase of $2.65 \mathrm{~g} \mathrm{~cm}^{-3} .{ }^{40}$ The assumed soil water pressure head at the micropore/macropore boundary was $-10 \mathrm{~cm}$ for all layers.

Parameters for crop development and crop uptake were based on observations, on the literature or on default values as supplied by the model. The soil moisture contents at the wilting point $\theta_{\mathrm{W}}$ (Table 1) were set according to the value of $\theta_{\mathrm{mi}}$ at a pressure head of $16000 \mathrm{~cm} .{ }^{41}$ Leaf area indexes at different times were estimated on the basis of light interception measurements made at the soil surface. ${ }^{42}$ The maximum root depth and the maximum crop height were based on field observations and set at 0.6 and $0.8 \mathrm{~m}$ respectively. It was assumed that $60 \%$ of the total root length was present in the top $20 \mathrm{~cm}$ of the soil profile.

The application of bromide at the experimental field in Andelst was intended to trace the water flow during the whole experimental period. However, about $80 \%$ of the bromide dose was taken up by the crop in the first month after application, and most of this was subsequently released into the soil in the next 2 months by the mineralization of litterfall. ${ }^{3}$ Therefore, the bromide behaviour in soil during the cropping period cannot be used to trace water flow. Hence, the bromide concentration profile measured at day 167 (all day numbers are days since bromide and bentazone application on 7 April 1998) was used as an initial condition, and MACRO was run from day 167 until the end of the experimental period. A dispersion length $\left[L_{\text {dis }}\right.$ in Eqn (7)] of $5 \mathrm{~cm}$ was set. The coefficient of bromide diffusion in water $\left[D_{0}\right.$ in Eqn (7)] was set at $2 \times 10^{-9} \mathrm{~m}^{2} \mathrm{~s}^{-1} \cdot{ }^{43}$ It was assumed for bromide that the excluded soil water content due to anion exclusion was $5 \%$ of the micropore volume fraction. The mixing depth $\left[z_{\mathrm{d}}\right.$ in Eqn (16)] was set at $1 \mathrm{~mm}$ for all simulations.

The dosage of bentazone used in the simulations was $1.4 \mathrm{~kg} \mathrm{ha}$ (the average amount recovered from soil 1 day after application). Input parameters for pesticide/soil interactions were obtained from laboratory studies ${ }^{3}$ and are shown in Table 2 . The half-lives of bentazone at reference conditions (i.e. $20^{\circ} \mathrm{C}$ and moisture content at pressure head of $-10 \mathrm{~cm}$ ) were 23.9 days for the $0-35 \mathrm{~cm}$ layer, 78.6 days for the $35-75 \mathrm{~cm}$ layer and 198 days for the $75-120 \mathrm{~cm}$ layer. These half-lives were based on laboratory experiments and converted to the reference conditions using the Arrhenius equation. The empirical exponent describing the effect of

Table 1. Soil properties and hydraulic parameters used as MACRO input

\begin{tabular}{|c|c|c|c|c|c|c|c|}
\hline \multirow[b]{2}{*}{ Input } & \multicolumn{6}{|c|}{ Layer (cm) } & \multirow[b]{2}{*}{ Derivation } \\
\hline & $0-10$ & $10-20$ & $20-35$ & $35-55$ & $55-75$ & $75-120$ & \\
\hline $\mathrm{OMC}(\%)^{\mathrm{a}}$ & 2.1 & 2.1 & 2.1 & 1.1 & 1.0 & 1.0 & Measured \\
\hline $\mathrm{BD}\left(\mathrm{g} \mathrm{cm}^{-3}\right)^{\mathrm{b}}$ & 1.47 & 1.47 & 1.51 & 1.52 & 1.52 & 1.50 & Measured \\
\hline$d(\mathrm{~mm})$ & 146 & 200 & 200 & 200 & 200 & 200 & Calibrated \\
\hline$h_{\mathrm{b}}(\mathrm{cm})$ & 10 & 10 & 10 & 10 & 10 & 10 & Assumed \\
\hline$\theta_{\mathrm{w}}\left(\mathrm{cm}^{3} \mathrm{~cm}^{-3}\right)$ & 0.22 & 0.22 & 0.23 & 0.18 & 0.26 & 0.24 & Fitted to VGC \\
\hline$n^{*}$ & 2 & 2 & 2 & 2 & 2 & 2 & Assumed \\
\hline$n$ & 1.100 & 1.100 & 1.108 & 1.093 & 1.074 & 1.087 & Fitted to VGC \\
\hline$\lambda$ & 0.5 & 0.5 & 0.5 & 0.5 & 0.5 & 0.5 & Assumed \\
\hline$\alpha\left(\mathrm{cm}^{-1}\right)$ & 0.019 & 0.019 & 0.075 & 0.017 & 0.012 & 0.008 & Fitted to VGc \\
\hline$K_{\mathrm{b}}\left(\mathrm{mm} \mathrm{h}^{-1}\right)$ & 0.45 & 0.45 & 0.45 & 0.45 & 0.45 & 0.45 & Calibrated \\
\hline$K_{\mathrm{S}}\left(\mathrm{mm} \mathrm{h}^{-1}\right)$ & 65 & 65 & 71 & 71 & 71 & 71 & Calibrated \\
\hline$\theta_{\mathrm{r}}\left(\mathrm{cm}^{3} \mathrm{~cm}^{-3}\right)$ & 0.01 & 0.01 & 0.01 & 0.01 & 0.01 & 0.01 & Fitted to VGC \\
\hline$\theta_{\mathrm{s}}\left(\mathrm{cm}^{3} \mathrm{~cm}^{-3}\right)$ & 0.43 & 0.43 & 0.41 & 0.41 & 0.41 & 0.42 & Fitted to VGC \\
\hline$\theta_{\mathrm{b}}\left(\mathrm{cm}^{3} \mathrm{~cm}^{-3}\right)$ & 0.423 & 0.423 & 0.388 & 0.405 & 0.407 & 0.418 & Fitted to VGC \\
\hline
\end{tabular}

a Organic matter content (\% by mass).

${ }^{\mathrm{b}}$ Dry soil bulk density.

c Fitted and derived from the Van Genuchten hydraulic functions. 
moisture content on degradation [ $B$ in Eqn (15)] was set at $0.7 .^{32}$ The parameter $\alpha$ in Eqn (14) was calculated using the following approximation: ${ }^{44}$

$$
\alpha=\frac{U}{700}
$$

where $U$ is the activation energy $\left(\mathrm{kJ} \mathrm{mol}^{-1}\right)$. Based on the $U$ value of $73.8 \mathrm{~kJ} \mathrm{~mol}^{-1}$ for bentazone, ${ }^{3}$ an $\alpha$ value of $0.105 \mathrm{~K}^{-1}$ was obtained using Eqn (19). The transpiration stream concentration factor for bentazone $\left[f_{\mathrm{u}}\right.$ in Eqn (12)] was assumed to be $0.78,{ }^{45}$ and $D_{0}$ was set at $4.9 \times 10^{-10} \mathrm{~m}^{2} \mathrm{~s}^{-1} \cdot{ }^{46}$ No significant sorption of bentazone could be measured in the Andelst clay soil, ${ }^{3}$ and the sorption coefficient of bentazone in the simulations was therefore set at zero (i.e. $K_{\mathrm{F}}=0$ ). It was assumed for bentazone that the excluded soil water content due to anion exclusion was $5 \%$ of the micropore volume fraction.

The dosage of imidacloprid used in the simulations was $0.55 \mathrm{~kg} \mathrm{ha}^{-1}$ (the average amount recovered from soil 2 days after application). The half-lives for imidacloprid at reference conditions were 90.2 days for the $0-35 \mathrm{~cm}$ layer, 174.5 days for the $35-75 \mathrm{~cm}$ layer and 445.7 days for the $75-120 \mathrm{~cm}$ layer. These half-lives were based on laboratory experiments and converted to the reference conditions using the Arrhenius equation. The exponent $B$ was set at $0.7,{ }^{32}$ and the parameter $\alpha$ was calculated to be $0.092 \mathrm{~K}^{-1}$ using a value of $U$ of $64.5 \mathrm{~kJ} \mathrm{~mol}^{-1}$ in Eqn (17). ${ }^{3}$ For imidacloprid, $f_{\mathrm{u}}$ was assumed to be $0.5,{ }^{47}$ and $D_{0}$ was set at $4.9 \times 10^{-10} \mathrm{~m}^{2} \mathrm{~s}^{-1} .46$ Freundlich sorption coefficients for imidacloprid $\left[K_{\mathrm{F}}\right.$ in Eqn (8)] in the Andelst topsoil $(0-30 \mathrm{~cm})$ were found to be $1.75 \mathrm{dm}^{3} \mathrm{~kg}^{-1}$ at $5^{\circ} \mathrm{C}, 1.51 \mathrm{dm}^{3} \mathrm{~kg}^{-1}$ at $15^{\circ} \mathrm{C}$ and $1.21 \mathrm{dm}^{3} \mathrm{~kg}^{-1}$ at $25^{\circ} \mathrm{C}^{3}$ It was decided to use $K_{\mathrm{F}}$ at $10^{\circ} \mathrm{C}$ as input because this is the annual average soil temperature in the Netherlands. The $K_{\mathrm{F}}$ values at different temperatures were fitted

Table 2. Selected properties of the tested pesticides

\begin{tabular}{|c|c|c|}
\hline \multirow[b]{2}{*}{ Properties $^{a}$} & \multicolumn{2}{|c|}{ Pesticides } \\
\hline & Bentazone & Imidacloprid \\
\hline$U\left(\mathrm{~kJ} \mathrm{~mol}^{-1}\right)$ & 73.8 & 64.5 \\
\hline$D_{0}\left(\mathrm{~m}^{2} \mathrm{~s}^{-1}\right)$ & $4.9 \times 10^{-10}$ & $4.9 \times 10^{-10}$ \\
\hline$K_{\mathrm{F}}\left(\mathrm{dm}^{3} \mathrm{~kg}^{-1}\right)$ & 0 & 1.61 \\
\hline$N$ & 0 & 0.81 \\
\hline$\alpha\left(\mathrm{K}^{-1}\right)$ & 0.105 & 0.092 \\
\hline$f_{\mathrm{u}}$ & 0.78 & 0.5 \\
\hline $\mathrm{DT}_{50_{\mathrm{REF}}}$ (days), 0-35 cm & 23.9 & 90.2 \\
\hline $\mathrm{DT}_{50_{\mathrm{REF}}}$ (days), $35-75 \mathrm{~cm}$ & 78.6 & 174.5 \\
\hline $\mathrm{DT}_{50_{\mathrm{REF}}}$ (days), $75-120 \mathrm{~cm}$ & 198 & 445.7 \\
\hline
\end{tabular}

${ }^{a} U$ is the activation energy, $D_{0}$ is the coefficient of pesticide diffusion in water, $K_{F}$ is the Freundlich sorption coefficient at $10^{\circ} \mathrm{C}, N$ is the exponent in the Freundlich isotherm, $\alpha$ is a composite parameter in the equation to account for the influence of soil temperature on the transformation rate of pesticides, $f_{\mathrm{u}}$ is the transpiration stream concentration factor and $\mathrm{DT}_{50_{\mathrm{REF}}}$ are the half-lives of pesticides at reference conditions (i.e. $20^{\circ} \mathrm{C}$ and moisture content at pressure head of $-10 \mathrm{~cm})$. to a Van't Hoff-type equation, which resulted in a sorption enthalpy of $12.7 \mathrm{~kJ} \mathrm{~mol}^{-1}$ and a $K_{\mathrm{F}}$ at $10^{\circ} \mathrm{C}$ of $1.61 \mathrm{dm}^{3} \mathrm{~kg}^{-1}$. Sorption in the subsoil was assumed to be proportional to soil organic matter content (Table 1), resulting in $K_{\mathrm{F}}$ values of $0.84 \mathrm{dm}^{3} \mathrm{~kg}^{-1}$ for the $35-55 \mathrm{~cm}$ layer and $0.77 \mathrm{dm}^{3} \mathrm{~kg}^{-1}$ for the $55-120 \mathrm{~cm}$ layer. The exponent in the Freundlich isotherm [ $N$ in Eqn (8)] was set at 0.81 , which was the average $N$ of the three sorption isotherms (0.81 at $5^{\circ} \mathrm{C}, 0.82$ at $15^{\circ} \mathrm{C}$ and 0.81 at $25^{\circ} \mathrm{C}$ ). An important parameter for MACRO simulations in macroporous soils is the fraction of sorption sites attributed to the macropores [ $f$ in Eqns (6) and (16)]. Fraction $f$ was fixed at the default value in the model (i.e. 0.02). Dubus et al. ${ }^{48}$ reported that $f$ values of between 0.01 and 0.04 are considered realistic for many soils.

The half-life for the pesticides was assumed to be the same in both phases and in both flow domains within each soil layer. Neither interception nor degradation of pesticides by the plant canopy was assumed, because the doses used in the simulations were based on the amount recovered in the soil profile 1 or 2 days after application.

\subsection{Calibration and testing procedure}

Simulations were carried out for the period from 21 January 1998 to 20 April 1999. Simulation results were compared with soil moisture contents, cumulative drain discharge, soil temperature, bromide and pesticide concentration profiles and bromide and pesticide concentrations in drain water and groundwater at different times.

The performance of MACRO was either assessed visually by graphical displays or by using statistical measures. For a graphical comparison, time series and concentration profiles of simulated and measured values are presented. The modelling efficiency (ME) was used to quantify the fit between model predictions and measurements of solute concentration depth profiles: ${ }^{49}$

$$
\mathrm{ME}=\frac{\sum_{i=1}^{n}\left(O_{i}-\bar{O}\right)^{2}-\sum_{i=1}^{n}\left(P_{i}-O_{i}\right)^{2}}{\sum_{i=1}^{n}\left(O_{i}-\bar{O}\right)^{2}}
$$

where $P_{i}$ is the predicted value, $O_{i}$ is the observed value, $\bar{O}$ is the average of the observed values and $n$ is the number of values. ME indicates whether the model describes the data better than simply the average of the measurements. The optimal value of $\mathrm{ME}$ is 1 . If the average of the measurements is used as the predictor, the value of $\mathrm{ME}$ becomes 0 .

The testing strategy adopted in this study was based on the recommendations of Armstrong et al. ${ }^{50}$ and Vanclooster et al. ${ }^{15}$ Firstly, the model was calibrated using the field measurements of water and bromide behaviour. Subsequently, simulations for bentazone and imidacloprid were carried out without further 
calibration. This strategy was adopted in order to test the predictive ability of the model in the context of exposure assessments in the EU, where scenarios may be precalibrated with respect to water flow and tracer transport, but where pesticide leaching predictions are uncalibrated. ${ }^{14}$

The testing procedure consisted of initially calibrating simultaneously the parameter $q_{\text {const }}$ [Eqn (5)] controlling percolation to groundwater, the aggregate half-width for layers $0-10 \mathrm{~cm}$ and $10-120 \mathrm{~cm}$ [ $d$ in Eqns (4) and (9)], the saturated hydraulic conductivity of the micropores for all layers $\left[K_{\mathrm{b}}\right.$ in Eqn (2)], the kinematic exponent $n^{*}$ [Eqn (2)] and the saturated hydraulic conductivity for layers $0-20 \mathrm{~cm}$ and $20-120 \mathrm{~cm}\left[K_{\mathrm{s}}\right.$ in Eqn (3)] against the data of moisture profiles, cumulative drain flow, bromide concentration profiles and bromide concentrations in drain water. This calibration was carried out using the SUFI program. ${ }^{51}$ These parameters were selected because of the difficulty and/or impossibility of direct measurement (i.e. $q_{\text {const }}, d, n^{*}$ ) or owing to the large uncertainty in deriving parameters from highly variable and uncertain measured data (i.e. $K_{\mathrm{b}}$ and $K_{\mathrm{s}}$ ). SUFI is a forward, sequential and iterative parameter estimation procedure that employs a global search of the parameter uncertainty domains. As a first step in SUFI, prior-uncertainty domains must be defined that should be large enough to include all physically reasonable values of the parameters on the basis of prior experience. Each uncertainty domain is divided into equidistant strata, and parameter values are defined as the first moment of each stratum. Then MACRO is run for each combination of parameter values and the simulations are compared with measured values in a goal function. In this study, the deviation between measured and simulated values was quantified by $\mathrm{ME}$ [Eqn (18)]. During this comparison, a critical value of the goal function (i.e. ME) is then defined, and any parameter value that fails to give any value of $\mathrm{ME}$ above the tolerance is eliminated. The subsequent iteration consists of repeating the above steps with reduced uncertainty domains. The procedure stops when the goal function cannot be minimized any more, or when it is not possible to reduce the uncertainty domains for the next iteration.

In a second calibration step, the effective aggregate half-width and the kinematic exponent were manually fine tuned to match tracer data obtained in individual flow events that were considered important for pesticide leaching, especially the initial breakthrough of solute to tile drains. These significant events, which were only of short duration, were not matched well by the initial automatic calibration since all data points were given equal weighting in the fitting procedure.

\section{RESULTS AND DISCUSSION}

\subsection{Calibrated parameter values}

The parameter controlling percolation to groundwater, $q_{\text {const }}$, was calibrated to $6.8 \times 10^{-13} \mathrm{~h}^{-1}$. This implies that the site hydrology was dominated by discharge to surface water via the drainage system. Indeed, this parameterization produced an upward flow of only $-7.9 \mathrm{~mm}$ between 7 April 1998 and 20 April 1999, while drain flow amounted to $576 \mathrm{~mm}$ during the same period. Hydraulic parameter values obtained by calibration against moisture profiles, cumulative drain water, bromide concentration profiles and bromide concentration in drain flow are shown in Table 1. It can be seen that $K_{\mathrm{s}}$ values were much larger than $K_{\mathrm{b}}$ values, which implies that macropores conducted water much faster than the soil matrix. The large $d$ values imply a high degree of physical non-equilibrium and are typical of structured soils exhibiting strong macropore flow. ${ }^{1,52}$ The kinematic exponent $n^{*}$ had to be set at its theoretical minimum value to match the initial tracer breakthrough to drains, which implies that transport was dominated by larger macropores of little tortuosity. Taken altogether, this parameterization implies that bromide and bentazone concentrations in drain flow should respond primarily to the macropores.

\subsection{Water and heat flow}

MACRO simulated the range and dynamics of the groundwater level during the whole experimental period reasonably well, with an EF value of 0.34 (Fig. 1). However, there were some discrepancies during the dry period. Simulated groundwater levels were too deep between days 50 and 150, and during the last days of the experimental period. A possible cause of these discrepancies could be the assumption of a linear dependence of percolation on the water table height in MACRO. Also, it is known that upward seepage of water occurred at the experimental field between days 202 and 219. ${ }^{3}$ Alternating downward and upward flows during the simulation are difficult to capture with the bottom boundary condition assumed in MACRO.

The moisture content in the $0-10 \mathrm{~cm}$ soil layer during the whole simulation period was overestimated (Fig. 2). This discrepancy was probably caused by

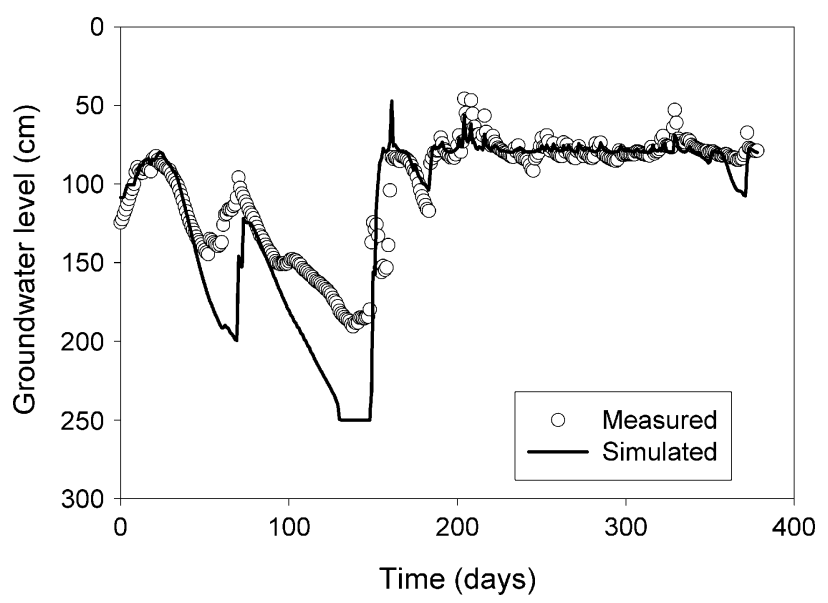

Figure 1. Measured and simulated groundwater levels during the experimental period. Day 0 is 7 April 1998. 

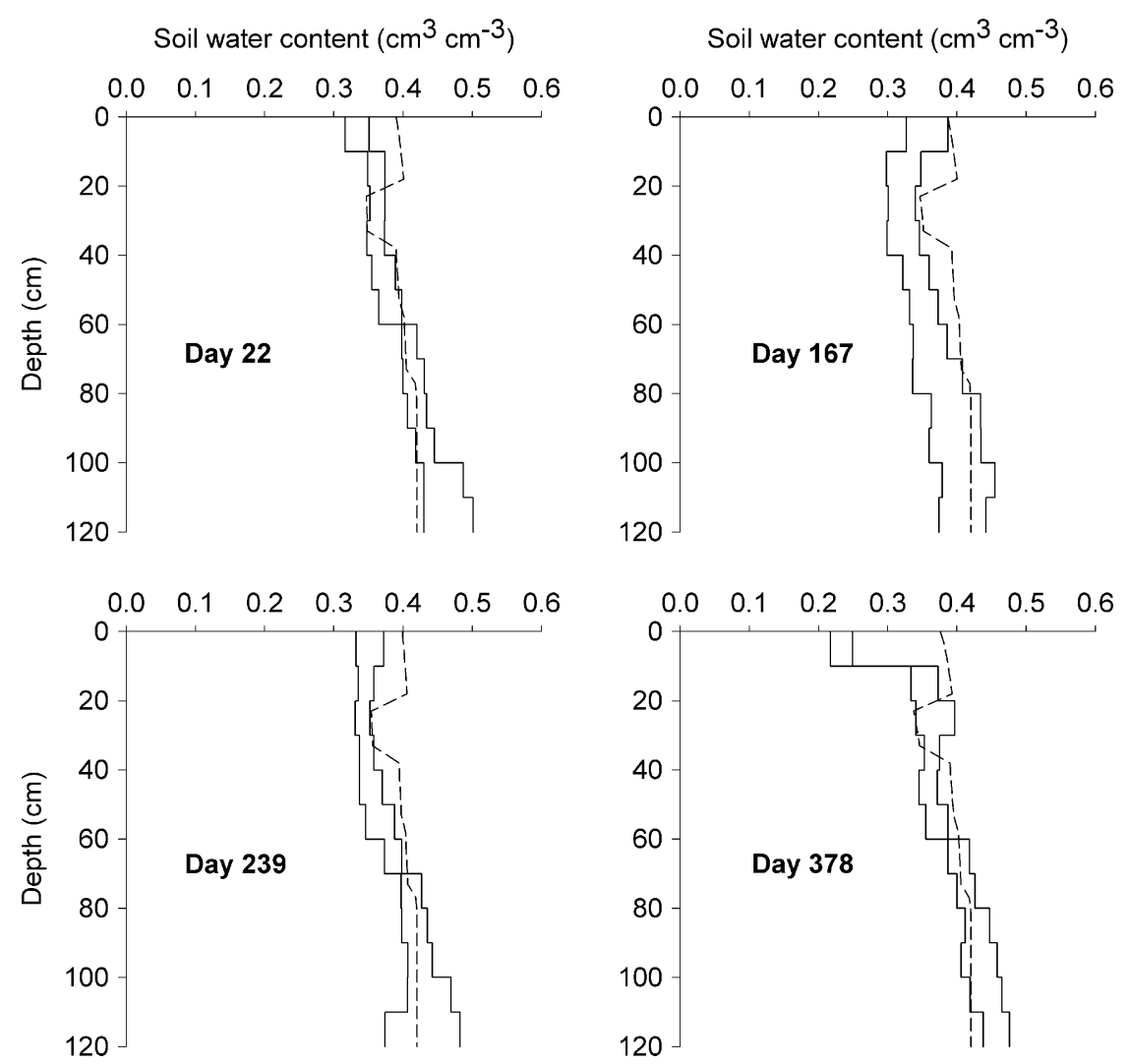

Figure 2. Measured and simulated soil moisture profiles at the experimental field after 22, 167, 239 and 378 days. The area within the solid lines is the range of the measured averages plus or minus 2 times the standard error. The dashed lines are the simulations. Day 0 is 7 April 1998.

the assumption that the hydraulic properties of this layer could be based on the measurements for the $10-20 \mathrm{~cm}$ layer, which is probably not realistic because the $0-10 \mathrm{~cm}$ layer had a bulk density about $20 \%$ smaller than that of the $10-20 \mathrm{~cm}$ layer (Table 1 ). In early spring in 1998 and 1999 (days 22 and 378), MACRO simulated the soil moisture contents below $10 \mathrm{~cm}$ depth fairly well $(\mathrm{EF}=0.49$ for day 22 and $\mathrm{EF}=0.28$ for day 378). In autumn (days 167 and 239), MACRO overestimated the soil moisture contents between 0 and $70 \mathrm{~cm}$ depth $(\mathrm{EF}=-0.51$ for day 167 and $\mathrm{EF}=0.30$ for day 239).

Figure 3 indicates that the cumulative drain discharge up to day 200 and after day 250 is overestimated with MACRO. However, between days 200 and 250 , the simulated cumulative drain discharge was within the measured range for drain sets 1 and 2 . The magnitude and timing of the drain discharges between days 160 and 260 were captured quite well with MACRO (Fig. 4). The comparison of drain discharges is restricted to this period, partly because the most important drain discharge events occurred at this time (Fig. 3), but also because the pattern shown in Fig. 4 was representative of other periods with drain discharge events.

Considering groundwater levels, moisture profiles and drain discharge rates, the authors conclude that this parameterization of MACRO described the overall site hydrology accurately enough.

A good simulation of soil temperature is a prerequisite for a reliable simulation of pesticide

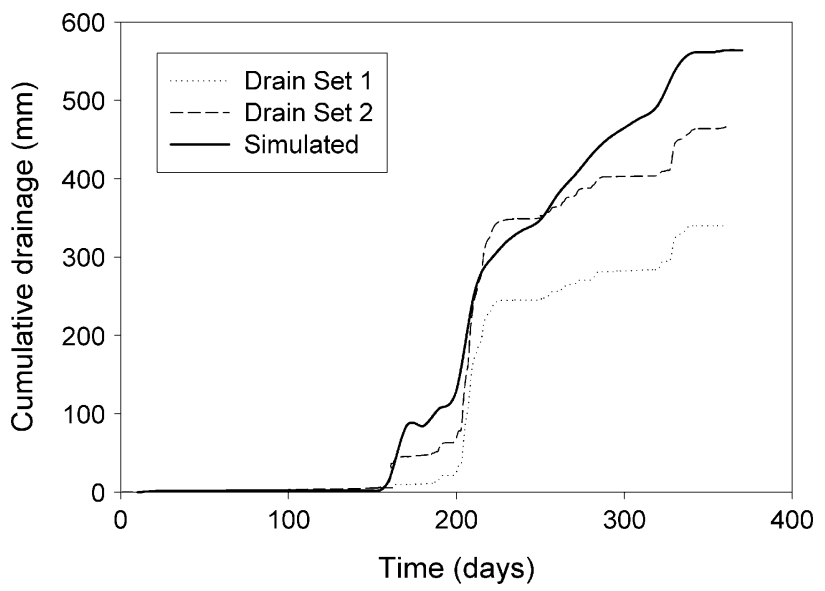

Figure 3. Measured and simulated cumulative drainage in both drain sets as a function of time. Time zero is 0:00 h on 7 April 1998.

degradation in the soil profile. The range and the dynamics of the simulated soil temperature at 5 and $50 \mathrm{~cm}$ depth corresponded well to the measurements, with a calculated average deviation between measured and simulated values of $0.21^{\circ} \mathrm{C}$ at $5 \mathrm{~cm}$ and $0.24^{\circ} \mathrm{C}$ at $50 \mathrm{~cm}$ depth.

\subsection{Bromide behaviour}

Bromide concentrations were rather evenly distributed with depth below $10 \mathrm{~cm}$ on day 239, but MACRO simulated the position of a peak at about $70 \mathrm{~cm}$ depth (Fig. 5). The negative value of ME, equal to -0.69 , confirms the poor simulation of bromide contents on 

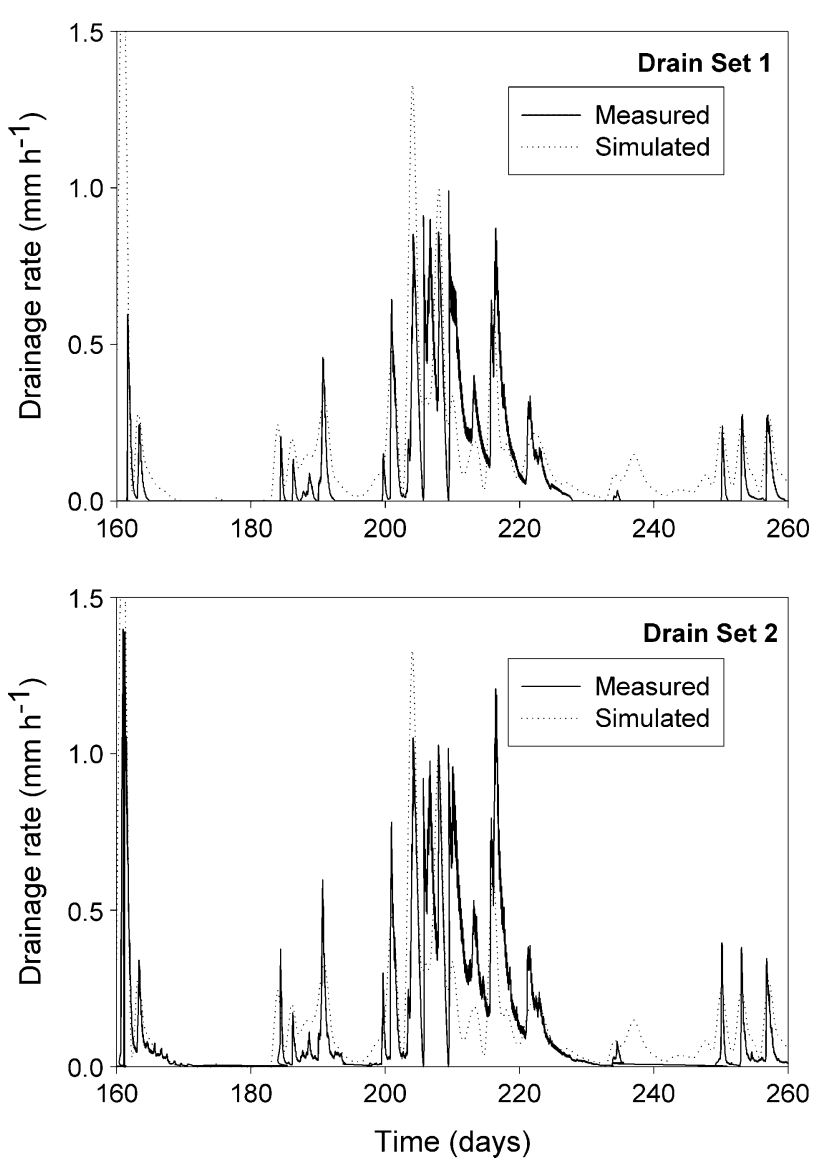

Figure 4. Measured and simulated tile drain discharge rates as a function of time between day 160 (i.e. 14 September 1998) and 260 (i.e. 23 December 1998).

day 239. However, on day 378 there was an excellent agreement between simulated and measured bromide concentration profiles, which is confirmed by the $\mathrm{ME}$ value of 0.95 .

Simulated bromide concentrations in the drain water were mainly between 2000 and $6000 \mu \mathrm{g} \mathrm{dm}^{-3}$ during the entire simulated period, which are mostly within the range of the measured values (see Fig. 9A). The overestimation of bromide concentrations in drain water between days 200 and 230 might be attributed to a dilution effect in the measured concentrations owing to the considerable upward seepage of water at the experimental field in this period. ${ }^{3}$ An upward seepage of water is also indicated by the fact that MACRO underpredicts measured drain flow during this period (Fig. 4).

The bromide concentration profile on day 239 was not described well with MACRO, in apparent contradiction to the fact that the bromide concentrations in drain water were described reasonably well (Figs 5 and 9A). The measured bromide content in the soil at $90 \mathrm{~cm}$ depth was about $1500 \mu \mathrm{g} \mathrm{dm}^{-3}$ (Fig. 5). This corresponds to a concentration in the soil water of about $3800 \mu \mathrm{g} \mathrm{dm}^{-3}$, assuming an average volume fraction of liquid phase of $0.4 \mathrm{~cm}^{3} \mathrm{~cm}^{-3}$ at $90 \mathrm{~cm}$ depth between days 167 and 378 (Fig. 2). Figure 9A shows that the measured bromide concentration in drain water was between 3000 and
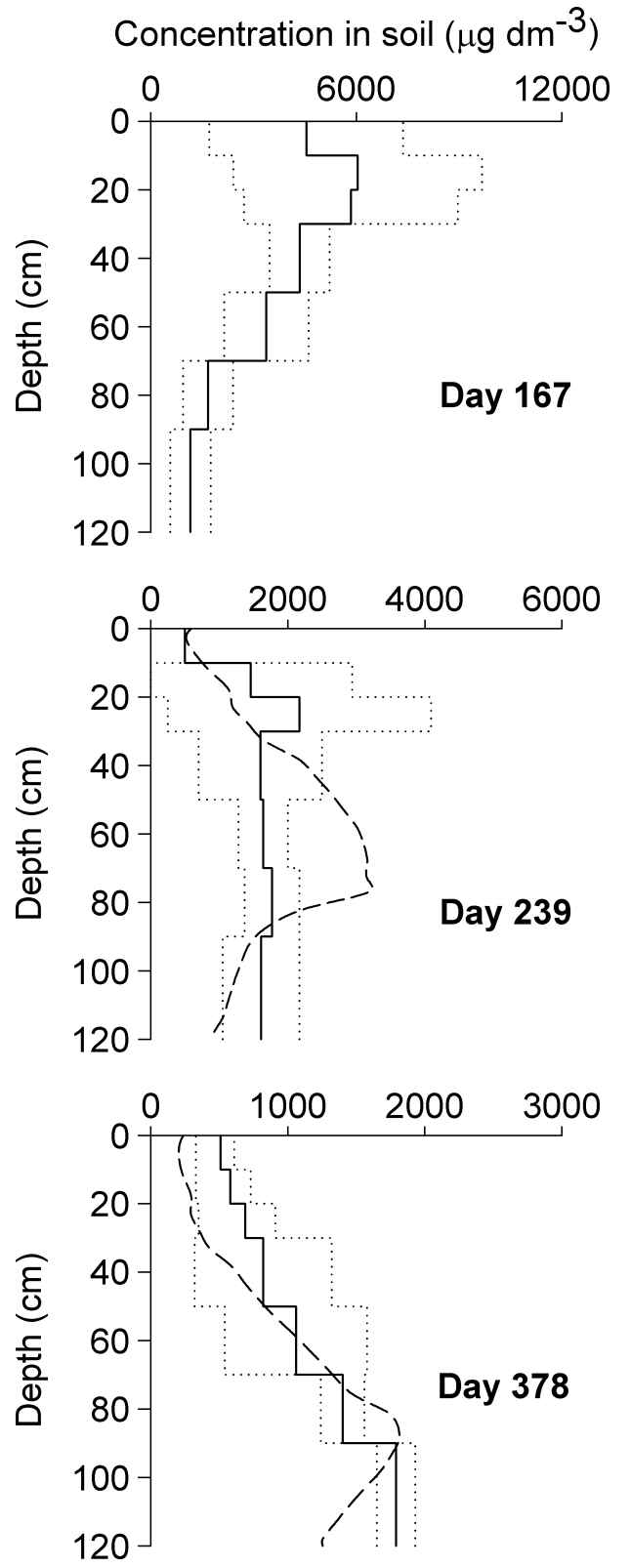

Figure 5. Measured and simulated bromide concentration profiles at 167,239 and 378 days after application. The solid lines are the average measured concentrations and the area within the dotted line is the range of measured averages plus and minus 2 times the standard error. The dashed lines are the simulated values. The solid line at day 167 is the initial concentration profile for simulations. In the simulations, the bromide concentrations below $120 \mathrm{~cm}$ depth at day 167 were assumed to be zero. Day 0 is 7 April 1998. Note that the horizontal axes have different scales.

$4000 \mu \mathrm{g} \mathrm{dm}^{-3}$ on day 239 , which corresponds well to a value of $3800 \mu \mathrm{g} \mathrm{dm}^{-3}$ at $90 \mathrm{~cm}$ depth in the soil profile. Therefore, the discrepancy between the measured and simulated bromide concentration profiles on day 239 did not lead to errors in the drain water concentrations, probably because it occurred mainly above the groundwater level.

Simulated bromide concentrations in the shallow groundwater $(1.0-1.2 \mathrm{~m})$ were within a factor 2 of those measured, but were underestimated between days 180 and 260, and overestimated between days 300 and 380 (see Fig. 10A). For the deep 
groundwater (1.3-1.5 m), MACRO underestimated bromide concentrations during the entire experimental period (see Fig. 10B).

\subsection{Bentazone behaviour}

The amount of bentazone in the soil profile was overestimated at all sampling dates (Fig. 6A). In a recent review, Beulke et al..$^{53}$ compared simulated and measured pesticide soil residues in the field using 178 studies for different soil types, pesticides and weather conditions. Their results showed that in $72 \%$ of the reviewed studies there was a tendency of the model to overestimate pesticide persistence in the field, based on laboratory-measured degradation rates. Different reasons have been attributed to faster degradation of pesticides in the field. Beulke et al. ${ }^{53}$ suggest that the decline of microbial biomass during soil incubation experiments and the use of static conditions in the laboratory experiments concerning temperature and moisture content are the main reasons for the discrepancies between laboratory and field half-lives. Moreover, Huber and Otto ${ }^{54}$ suggest that, under field conditions, the degradation of bentazone occurs with alternating wetting and drying of the topsoil, which stimulates microbial activity by improving oxygen supply, and thus a faster degradation in the field than in laboratory incubation studies may be expected. Based on these two studies, ${ }^{53,54}$ it is concluded that there are some difficulties in characterizing pesticide degradation under field conditions using laboratory studies. Although the specific causes of the faster degradation of bentazone in the present field experiment are not known, it is clear that underestimation of the degradation rate can seriously influence leaching losses estimated with models, since these are generally very sensitive to degradation. ${ }^{55-57}$

Bentazone concentration profiles in Fig. 7 show that bentazone concentrations were overestimated between 0 and $20 \mathrm{~cm}$ depth and underestimated between 30 and $70 \mathrm{~cm}$ depth at day 22. At days 69 and 125, bentazone concentrations were overestimated between
0 and $40 \mathrm{~cm}$ depth. Bentazone concentrations in the soil profile below $5 \mathrm{~cm}$ depth at day 239 were strongly overestimated by MACRO. ME values for bentazone concentration profiles at days 22, 69 and 125 were $-0.28,-3.42$ and -10.41 respectively, indicating poor simulation. The ME value was not calculated for day 239 because measured concentrations below $30 \mathrm{~cm}$ depth were below the limit of quantification.

The bulk of the bentazone movement in the soil profile after 22, 69 and 125 days was underestimated with MACRO (Fig. 7), perhaps because the degree of physical non-equilibrium was overestimated. MACRO was calibrated using bromide measurements in autumn and winter, whereas bentazone transport was monitored in spring and summer. This difference in seasons may involve temporal variations in soil hydraulic characteristics and thus variations in the partitioning of water flow between micropores and macropores. ${ }^{58,59}$

MACRO simulated the dynamics of the bentazone breakthrough in drain water well during the entire experimental period (see Fig. 9B). In particular, MACRO accurately simulated the timing of the initial breakthrough of bentazone in drain water. The bentazone concentration in drain water between days 240 and 330 remained at around $4 \mu \mathrm{g} \mathrm{dm}^{-3}$ (Fig. 9B), whereas the concentration in soil on day 239 was below the LOQ of $0.8 \mu \mathrm{g} \mathrm{dm}^{-3}$ for the entire soil profile (Fig. 7). The LOQ of $0.8 \mu \mathrm{g} \mathrm{dm}^{-3}$ implies a maximum bentazone concentration of $2 \mu \mathrm{g} \mathrm{dm}^{-3}$ in soil pore water, which is about 2 times lower than measured in drain water. Therefore, the source of the bentazone leached in the drain flow between days 240 and 330 (which corresponds to ca $0.1 \%$ of the dose) is not clear. It is possible that the soil contained a higher total concentration than was extracted. Bentazone was extracted by shaking for 1 hour with aqueous calcium chloride solution. ${ }^{3}$ It was checked that this procedure gave good recoveries for fresh residues. However, this is not a guarantee that the extraction is adequate for aged residues, ${ }^{60}$ and slow sorption may have occurred
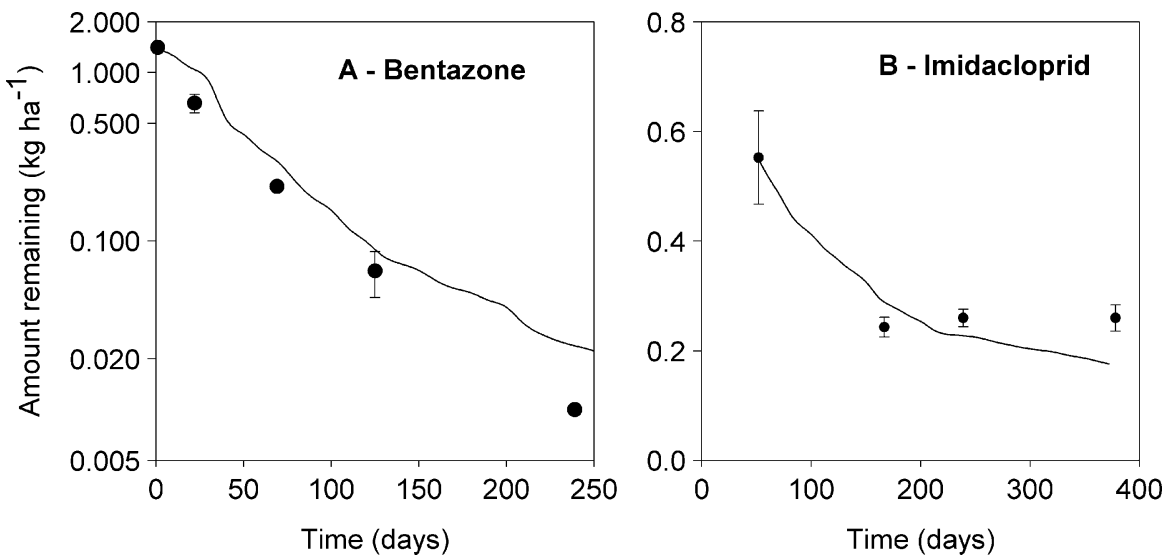

Figure 6. Comparison of measured and simulated total amount of (A) bentazone and (B) imidacloprid in the top $120 \mathrm{~cm}$ of the soil profile. Points are measurements and bars are the standard errors. Solid lines are simulations. Time zero is 7 April 1998. Note that both the vertical and the horizontal axes have different scales in parts $\mathrm{A}$ and $\mathrm{B}$. 


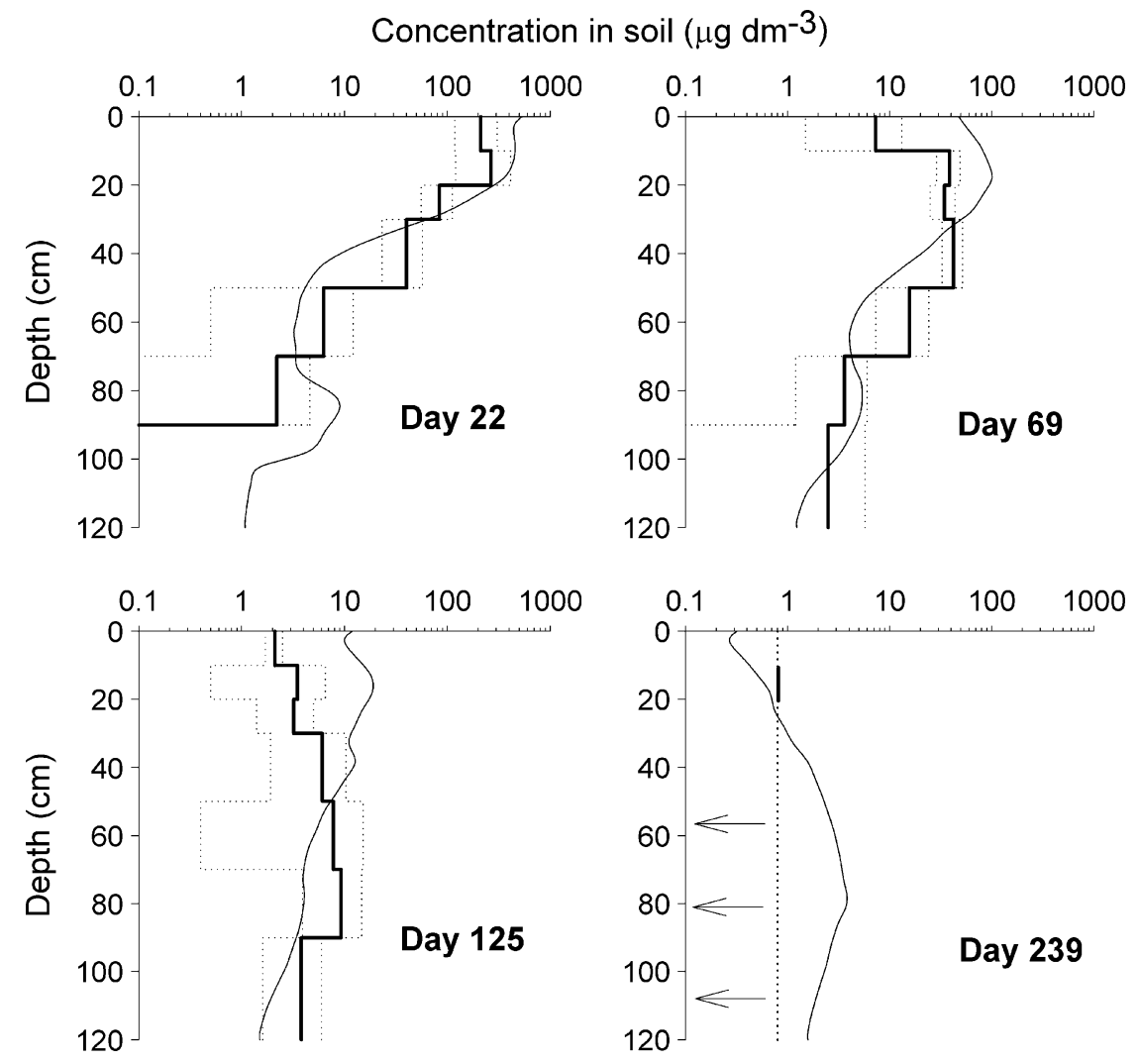

Figure 7. Measured and simulated bentazone concentration profiles at 22, 69, 125 and 239 days after application. The thick solid line is the average measured concentration and the area within the dotted lines is the range of the measured averages plus and minus 2 times the standard error. The thin solid line is the simulation. The vertical dotted line at day 239 is the limit of quantification as indicated by the arrows, and bentazone was only measurable in the $10-20 \mathrm{~cm}$ soil layer at levels of up to $0.8 \mu \mathrm{g} \mathrm{dm}^{-3}$. Day 0 is 7 April 1998.

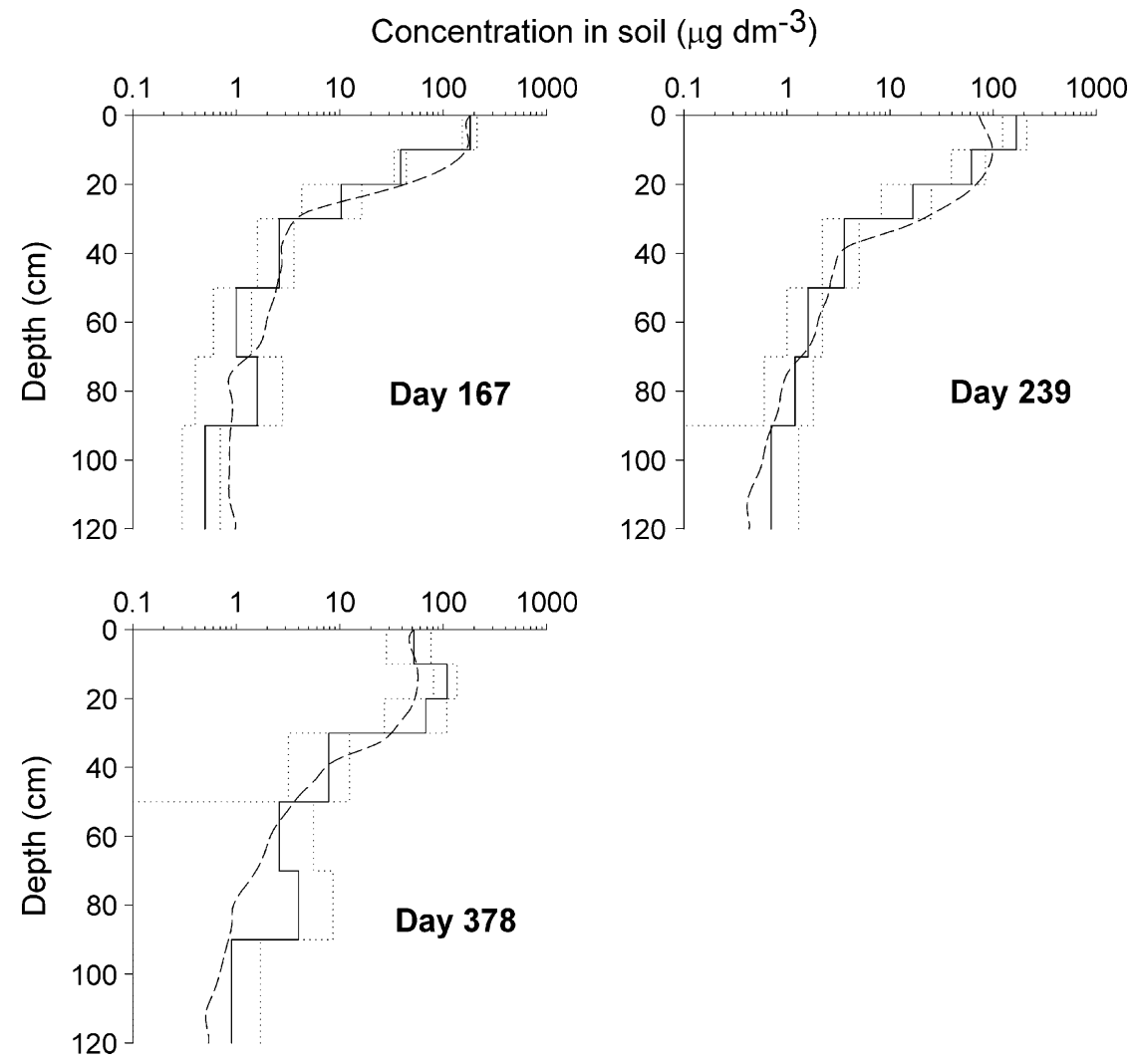

Figure 8. Measured and simulated imidacloprid concentration profiles at days 167,239 and 378 . The solid line is the average of measured concentrations and the area within the dotted line is the range of measured averages plus and minus 2 times the standard error. The dashed line was simulated. Day 0 is 7 April 1998, and imidacloprid was applied at day 50. 
that was not detected via the present extraction. ${ }^{61}$ This also suggests that the simulation of the bentazone depth profile on day 239 may be better than it might appear at first sight.

As shown by the simulated concentration profiles in Fig. 7, the bulk of the bentazone leaching was apparently underestimated with MACRO during the entire simulation period. However, it simulated the dynamics of the initial bentazone breakthrough in drain water rather well (Fig. 9B). This discrepancy between simulated concentration profiles and simulated concentrations in drain water can probably be explained by the two flow domains (i.e. micropores and macropores) that operate semi-independently in MACRO. The parameterization used in MACRO for the Andelst soil indicates a high degree of physical non-equilibrium and thus emphasizes the flow in the macropores. Therefore, the good description of the early breakthrough of bentazone in drain water suggests that MACRO could capture satisfactorily the main process (i.e. macropore flow) regulating this transport.

MACRO simulated the timing of the bentazone breakthrough in the groundwater at $1.0-1.2 \mathrm{~m}$ depth well, but underestimated the concentration (see Fig. 10C). The simulated bentazone concentrations in groundwater were almost constant at a value of $5 \mu \mathrm{g} \mathrm{dm}^{-3}$, which resulted in an overestimation after day 170. The simulated bentazone concentrations at $1.3-1.5 \mathrm{~m}$ depth showed a fairly good agreement with the measurements. However, the bentazon peak that occurred at about day 150 could not be simulated with MACRO (see Fig. 10D). The failure of MACRO to describe the magnitude of the initial concentration peak in the groundwater at $1.0-1.2 \mathrm{~m}$ depth may be the cause of the poor simulation for the 1.3-1.5 depth because the concentration peak of bentazone moves downwards.

\subsection{Imidacloprid behaviour}

MACRO simulated the decline of total areic mass of imidacloprid in the soil profile well (Fig. 6B). The measured values after day 167 were almost constant with time, indicating very slow dissipation during winter. However, MACRO simulated a slight decline after day 167. The comparison of measured and simulated imidacloprid concentration profiles in Fig. 8 shows that MACRO simulated the leaching of this substance reasonably well, with $\mathrm{EF}$ values between 0.64 and 0.85 .

The timing of the imidacloprid breakthrough in drain water around day 180 was well simulated by MACRO, whereas the simulated concentrations were 3 times larger than measured (Fig. 9C). MACRO overestimated imidacloprid concentrations between days 190 and 220 (a period of intensive drain discharge) (see Fig. 4). An important MACRO parameter for simulation of sorbed substances is the fraction of sorption sites attributed to macropores [ $f$ in Eqns (6) and (16)]. There is considerable
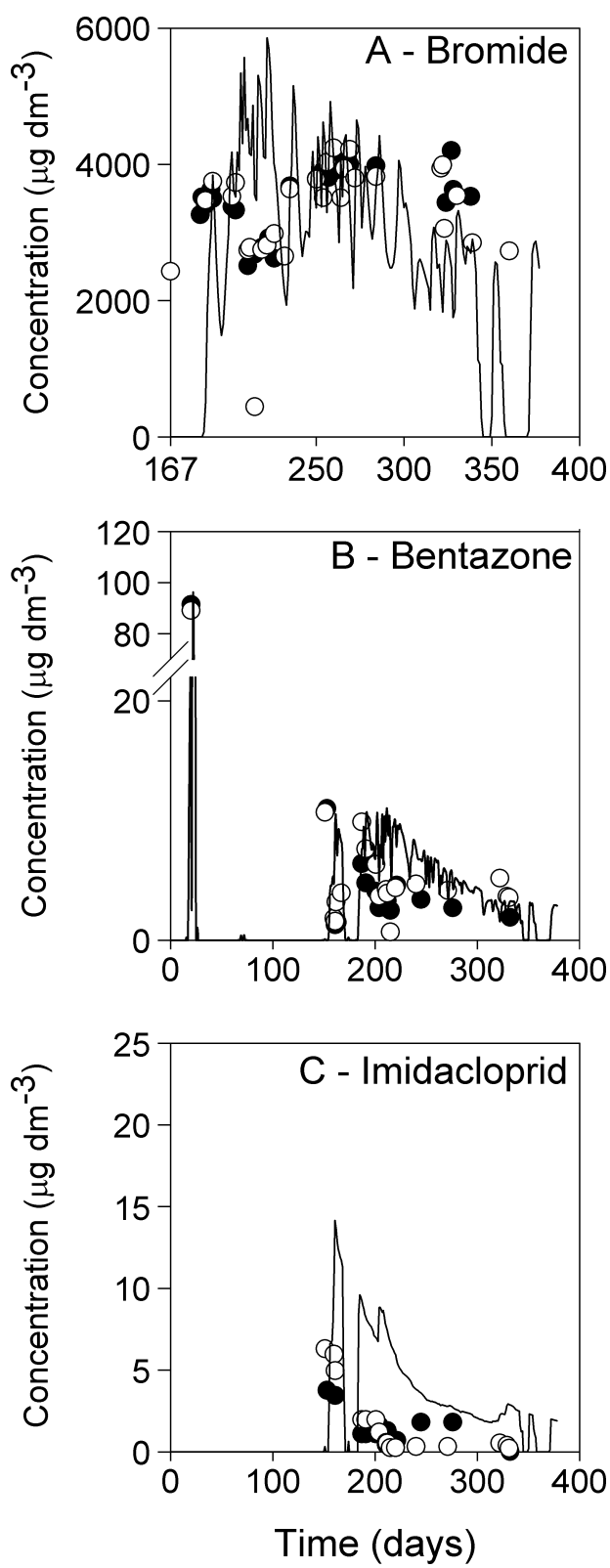

Figure 9. Measured and simulated (A) bromide, $(\mathrm{B})$ bentazone and (C) imidacloprid concentrations in drain water as a function of time. Points are measurements and lines are simulations. Time zero is 0:00 $\mathrm{h}$ at 7 April 1998, and imidacloprid was applied at day 50.

uncertainty in the estimation of this parameter, and there is evidence that pesticides can be strongly sorbed to macropore coatings and linings that have larger organic carbon contents owing to biological activity. ${ }^{62}$ The present authors therefore investigated the sensitivity to this parameter. Because MACRO overpredicted the concentrations in drain water (Fig. 9C), a calculation was made with an upper limit of $f$ of 0.04 , as proposed by Dubus et al., ${ }^{48}$ which is 2 times the original $f$ value of 0.02 . However, increasing $f$ to 0.04 only decreased the simulated imidacloprid concentration in drain water by $2 \%$.

MACRO underestimated imidacloprid concentrations in the groundwater at $1.0-1.2 \mathrm{~m}$ and $1.3-1.5 \mathrm{~m}$ depth by a factor of up to 5 during the experimental period, with the exception of one measurement 

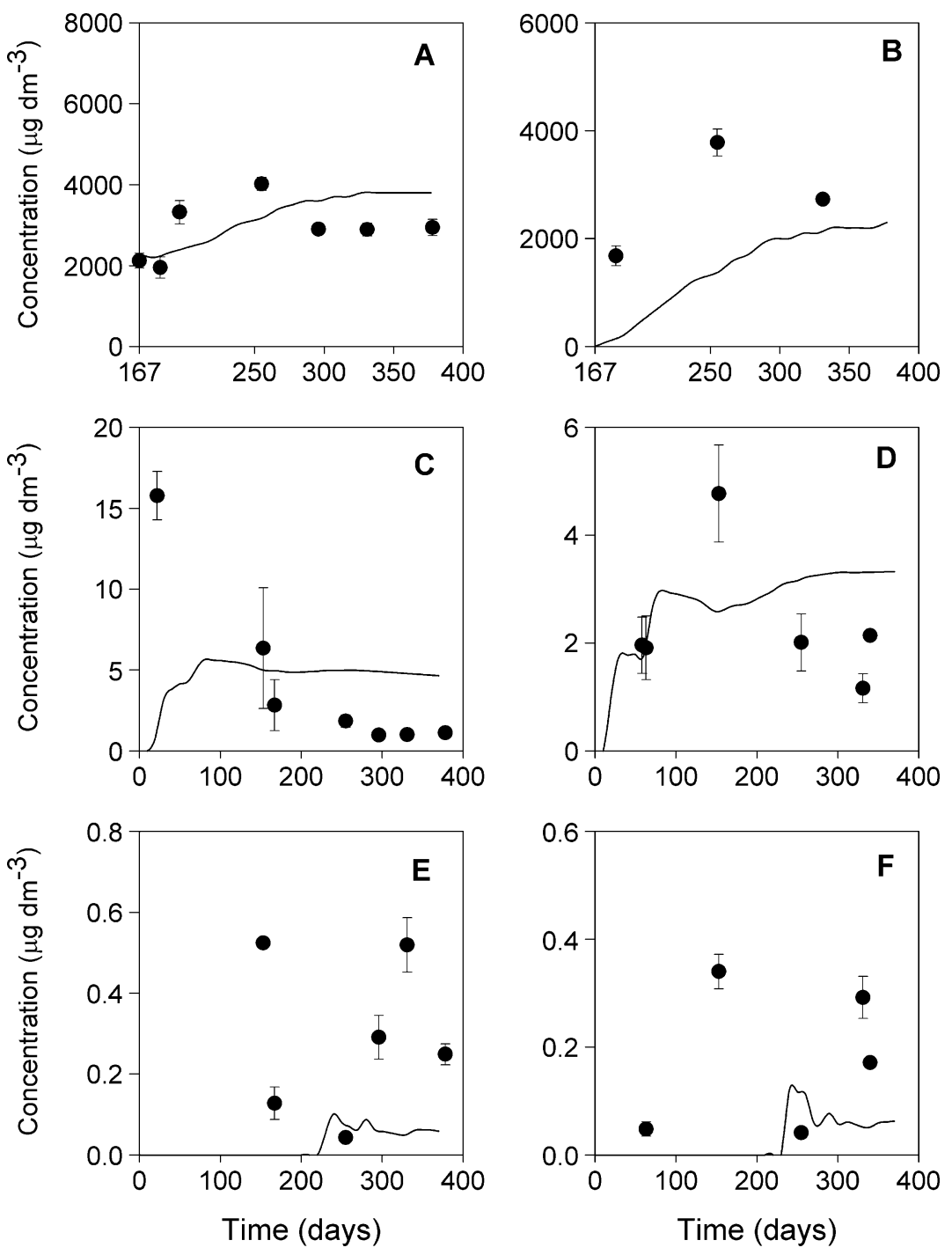

Figure 10. Measured and simulated bromide (A, B), bentazone (C, D) and imidacloprid (E, F) concentrations in groundwater at filter depths of 1.0-1.2 $\mathrm{m} \mathrm{(A,} \mathrm{C,} \mathrm{E)} \mathrm{and} \mathrm{1.3-1.5} \mathrm{m} \mathrm{(B,} \mathrm{D,} \mathrm{F)} \mathrm{as} \mathrm{a} \mathrm{function} \mathrm{of} \mathrm{time.} \mathrm{Points} \mathrm{are} \mathrm{the} \mathrm{measured} \mathrm{averages} \mathrm{and} \mathrm{bars} \mathrm{are} \mathrm{the} \mathrm{standard} \mathrm{errors.} \mathrm{Lines} \mathrm{are}$ simulations. Time zero is 7 April 1998, and imidacloprid was applied at day 50. Note that the vertical axes have different scales.

at about day 250 (Figs $10 \mathrm{E}$ and F). The early breakthrough of imidacloprid in the groundwater at $1.3-1.5 \mathrm{~m}$ depth was not predicted by MACRO (Fig. 10F).

\section{CONCLUSIONS}

Calibration against the measurements of soil water content and bromide concentration in soil and in drain water indicated that a high degree of physical non-equilibrium was necessary to accurately describe the solute transport in this cracking clay soil. Using laboratory input data, MACRO overestimated bentazone persistence in the field. In contrast, MACRO described the imidacloprid persistence well. The bulk of the bentazone movement in this soil was underestimated by MACRO, but the timing and the concentration level of the early breakthrough of bentazone in drain water as a result of macropore flow was accurately simulated. MACRO simulated the concentration profiles of the strongly sorbed substance imidacloprid reasonably well, although it overpredicted the concentrations of this substance in the drain water during intensive drain discharges. As a heavy clay soil, Andelst can be considered as a good example of a typical scenario for surface water risk assessment for pesticides, since discharge to drains dominates the site hydrology. In the context of FOCUS, ${ }^{14}$ most emphasis should therefore be placed on the accuracy of the model simulations of maximum concentrations in drain water, because these are the main drivers of the ecotoxicological risk assessment. In this respect, and considering the uncertainties involved, MACRO gave quite accurate predictions for both bentazone and imidacloprid, with simulated concentrations within a factor of 3 at worst.

\section{ACKNOWLEDGEMENTS}

The authors would like to thank the Fundação Coordenação de Aperfeiçoamento de Pessoal de Nível Superior - CAPES (Brazil) and the Dutch Ministry for Agriculture, Nature and Food Safety. 


\section{REFERENCES}

1 Larsson MH and Jarvis NJ, Evaluation of a dual-porosity model to predict field-scale solute transport in a macroporous soil. $\mathcal{F}$ Hydrol 215:153-171 (1999).

2 Zehe E and Flühler H, Preferential transport of isoproturon at a plot scale and a field scale tile-drained site. $\mathcal{F}$ Hydrol 247:100-115 (2001)

3 Scorza Júnior RP, Smelt JH, Boesten JJTI, Hendriks RFA and van der Zee SEATM, Preferential transport of bromide, bentazone and imidacloprid in a Dutch clay soil. $\mathcal{F}$ Environ Qual 33:1473-1486 (2004).

4 Flury M, Experimental evidence of transport of pesticides through field soils - a review. I Environ Qual 25:25-45 (1996).

5 Larsson $\mathrm{MH}$ and Jarvis NJ, Quantifying interactions between compound properties and macropore flow effects on pesticide leaching. Pest Manag Sci 56:133-141 (2000).

6 Barraclough D, A usable mechanistic model of nitrate leaching. I. The model. F Soil Sci 40:543-554 (1989).

7 Corwin DL, Waggoner BL and Rhoades JD, A functional model of solute transport that accounts for bypass. F Environ Qual 20:647-658 (1991).

8 Hall DGM, An amended functional leaching model applicable to structured soils. I. Model description. F Soil Sci 44:579-588 (1993).

9 Hutson JL and Wagenet RJ, A pragmatic field-scale approach for modeling pesticides. F Environ Qual 22:494-499 (1993).

10 Hutson JL and Wagenet RJ, A multi-region model describing water flow and solute transport in heterogeneous soils. Soil Sci Soc Am f 59:743-751 (1995).

11 Larsbo $M$ and Jarvis NJ, MACRO 5.0. A model of water flow and solute transport in macroporous soil. Technical description. Rep Emergo 2003:6, Swedish University of Agricultural Sciences, Uppsala, Sweden, 48 pp. (2003).

12 Leaching models and EU registration. FOCUS. EC document reference 4952/VI/95, $123 \mathrm{pp}$. (1995).

13 Surface water models and EU registration of plant protection products. FOCUS. EC document reference 6476/VI/96, 231 pp. (1997).

14 Surface water scenarios in the EU evaluation process under 91/414/EEC. FOCUS. EC document reference SANCO/4802/2001-rev 2, 245 pp. (2001).

15 Vanclooster M, Boesten JJTI, Trevisan M, Brown CD, Capri E, Eklo OM et al., A European test of pesticide-leaching models: methodology and major recommendations. Agric Water Manag 44:1-19 (2000).

16 Larsbo $M$ and Jarvis NJ, Simulating solute transport in a structured field soil: uncertainty in parameter identification and predictions. F Environ Qual 34:621-634 (2001).

17 van Genuchten MTh, A closed form equation for predicting the hydraulic conductivity of unsaturated soils. Soil Sci Soc Am F 44:892-898 (1980).

18 Mualem Y, A new model for predicting the hydraulic conductivity of unsaturated porous media. Water Resour Res 12:513-522 (1976).

19 van Genuchten MTh and Dalton FN, Models for simulating salt movement in aggregated field soils. Geoderma 38:165-183 (1986).

20 Booltink HWG, Hatano R and Bouma J, Measurement and simulation of bypass flow in a structured clay soil: a physicomorphological approach. F Hydrol 148:149-168 (1993).

21 Gerke HH and van Genuchten MTh, Macroscopic representation of structural geometry for simulating water and solute movement in dual-porosity media. Adv Water Res 19:343-357 (1996).

22 Gerke HH and van Genuchten MTh, Evaluation of a first-order water transfer term for variably-saturated dual-porosity flow models. Water Resour Res 29:1225-1238 (1993).

23 Jarvis NJ, The MACRO Model (Version 3.1). Technical description and sample simulations. Reports and Dissertations 19, Department of Soil Science, Swedish University of Agricultural Sciences, Uppsala, Sweden, 51 pp. (1994).
24 Monteith JL, Evaporation and environment, in The State and Movement of Water in Living Organisms, 19th Symp Soc Exp Biol, ed. by Fogg GR. Cambridge University Press, London, pp. 205-234 (1965).

25 Jarvis NJ, A simple empirical model for root water uptake. $\mathcal{F}$ Hydrol 107:57-72 (1989).

26 Beven K and Germann P, Water flow in soil macropores. II. A combined flow model. F Soil Sci 32:15-29 (1981).

27 Bronswijk JJB, Modeling of water balance, cracking and subsidence of clay soils. F Hydrol 97:199-212 (1988).

28 Leeds-Harrison PB, Shipway CJP, Jarvis NJ and Youngs EG, The influence of soil macroporosity on water retention, transmission and drainage in clay soil. Soil Use Manag 2:47-50 (1986).

29 Millington RJ and Quirk JP, Permeability of porous solids. Trans Faraday Soc 57:1200-1207 (1961).

30 Boesten JJTI, Simulation of bentazon leaching in sandy loam soil from Mellby (Sweden) with the PESTLA model. If Environ Sci Health Part A 29:1231-1253 (1994).

31 Valocchi AJ, Use of temporal moment analysis to study reactive transport in aggregated porous media. Geoderma 46:233-247 (1990).

32 Boesten JJTI and van der Linden AMA, Modeling the influence of sorption and transformation on pesticide leaching and persistence. F Environ Qual 20:425-435 (1991).

33 Steenhuis TS and Walter MF, Closed form solution for pesticide loss in runoff water. Trans ASAE 23:615-620, 628 (1980).

34 KNMI, Kimaatlas van Nederland, de normaalperiode 1971-2000. Elmar, The Netherlands (2002).

35 Soil of the world. Revised legend. World Soil Resources, Report 64, FAO, Rome (1998).

36 Halbertsma JM and Veerman GJ, Determination of the unsaturated conductivity and water retention characteristic using the Wind's evaporation method, in Manual for Soil Physical Measurements, Version 3.0, ed. by Stolte J. Technical Document 37, DLO Winand Staring Centre, Wageningen, The Netherlands, pp. 47-55 (1997).

37 Stolte J, Determination of the saturated conductivity using the constant head method, in Manual for Soil Physical Measurements, Version 3.0, ed. by Stolte J. Technical Document 37, DLO Winand Staring Centre, Wageningen, The Netherlands, pp. 27-32 (1997).

38 Scorza Júnior RP, Pesticide leaching in macroporous clay soils: field experiment and modeling. PhD Thesis, Wageningen University and Research Centre, Wageningen, The Netherlands, 234 pp. (2002).

39 van Genuchten MTh, Leij FJ and Yates SR, The RETC Code for Quantifying the Hydraulic Functions of Unsaturated Soils. US Salinity Lab, Riverside, CA, USA (1991).

40 Koorevaar P, Menelik G and Dirksen C, Developments in Soil Science 13: Elements of Soil Physics. Elsevier, Amsterdam, The Netherlands (1983).

41 Wesseling JG, Meerjarige simulaties van grondwateronttrekking voor verschillende bodemprofielen, grondwatertrappen en gewassen met het model SWATRE (in Dutch with English summary). Winand Staring Centre Rep 152, Winand Staring Centre, Wageningen, The Netherlands, 63 pp. (1991).

42 Smelt JH, Hendriks RFA, van der Pas LJT, Matser AM, van den Toorn A, Oostindie K et al., Transport of water, bromide ion, nutrients and the pesticides bentazone and imidacloprid in a cracking, tile drained clay soil at Andelst, The Netherlands, Alterra Rep 289, Wageningen University and Research Centre, Wageningen, The Netherlands, 213 pp. (2003).

43 Weast RC, Handbook of Chemistry and Physics. CRC Press, Cleveland, OH, USA (1974).

44 Boesten JJTI, Behaviour of herbicides in soil: simulation and experimental assessment. PhD Thesis, Institute for Pesticide Research, Wageningen, The Netherlands, 263 pp. (1986).

45 Ciucani G, Trevisan M, Sacchi GA and Trapp SAJ, Measurement of xylem translocation of weak electrolytes with the 
pressure chamber technique. Pest Manag Sci 58:467-473 (2002).

46 Jury WA, Spencer WF and Farmer WJ, Behavior assessment model for trace organics in soil. I. Model description. $\mathcal{f}$ Environ Qual 12:558-564 (1983).

47 Groundwater scenarios in the EU plant protection review process. FOCUS. EC document reference Sanco/321/2000 rev 2, 202 pp. (2000).

48 Dubus IG, Beulke $\mathrm{S}$ and Brown CD, A briefing document on the application of inverse modeling techniques to pesticide leaching models. SSLRC Rep PL0528, Cranfield University, Silsoe, 45 pp. (2000).

49 Janssen PHM and Heuberger PSC, Calibration of processoriented models. Ecol Model 83:55-66 (1995).

50 Armstrong AC, Portwood AM, Leeds-Harrison PB, Harris GL and Catt JA, The validation of pesticide leaching models. Pestic Sci 48:47-55 (1996).

51 Abbaspour KC, van Genuchten MTh, Schulin R and Schläppi E, A sequential uncertainty domain inverse procedure for estimating subsurface flow and transport parameters. Water Resour Res 33:1879-1892 (1997).

52 Roulier S and Jarvis NJ, Modeling macropore flow effects on pesticide leaching: inverse parameter estimation using microlysimeters. F Environ Qual 32:2341-2353 (2003).

53 Beulke S, Dubus IG, Brown CD and Gottesbüren B, Simulation of pesticide persistence in the field on the basis of laboratory data - a review. F Environ Qual 29:1371-1379 (2000).
54 Huber R and Otto S, Environmental behavior of bentazon herbicide. Rev Environ Contam Toxicol 137:111-134 (1994).

55 Leonard RA, Knisel WG and Still DA, GLEAMS: ground water loading effects of agricultural management systems. Trans ASAE 30:1403-1418 (1987).

56 Boesten JJTI, Sensitivity analysis of a mathematical model for pesticide leaching to ground water. Pestic Sci 31:375-388 (1991).

57 Soutter $M$ and Musy A, Global sensitivity analyses of three pesticide leaching models using a Monte-Carlo approach. $\mathcal{F}$ Environ Qual 28:1290-1297 (1999).

58 Singh B, Chanasky DS and McGill WB, Soil hydraulic properties of an Orthic Black Chernozem under long-term tillage and residue management. Can F Soil Sci 76:63-71 (1996).

59 Messing L and Jarvis NJ, Temporal variation in the hydraulic conductivity of a tilled clay soil as measured by tension infiltrometers. F Soil Sci 44:11-24 (1993).

60 Smith AE, Comparison of solvent systems for the extraction of atrazine, benzoylprop, flamprop, and trifluralin from weathered field soils. F Agric Food Chem 29:111-115 (1981).

61 Boesten JJTI and Gottesbüren B, Testing PESTLA using two modelers for bentazone and ethoprophos in a sandy soil. Agric Water Manag 44:283-305 (2000).

62 Mallawatantri AP, McConkey BG and Mulla DJ, Characterisation of pesticide sorption and degradation in macropore linings and soil horizons of Thatuna silt loam. F Environ Qual 25:227-235 (1996). 